\title{
Transforming growth factor- $\beta 1$ treatment of oral cancer induces epithelial-mesenchymal transition and promotes bone invasion via enhanced activity of osteoclasts
}

\author{
Jingjing Quan • Moustafa Elhousiny • \\ Newell W. Johnson • Jin Gao
}

Received: 4 June 2012/ Accepted: 18 January 2013/Published online: 2 February 2013

(c) The Author(s) 2013. This article is published with open access at Springerlink.com

\begin{abstract}
This study investigates relationships between EMT and bone invasion by OSCC. Three OSCC cell lines, SCC25, HN5, and Tca8113 were artificially induced to display EMT by adding $5 \mathrm{ng} / \mathrm{mL}$ of TGF- $\beta 1$ to culture media for 1-3 days. Cell morphology and phenotypic changes was examined by immunocytochemical staining of CK and VIM. EMT markers, cell-invasion factors, and osteoclast-related molecules were analysed at mRNA, gelatine and protein levels by real-time PCR, gelatine zymography and Western blotting respectively. Mature osteoclasts differentiated from Raw264.7 cells were treated by conditioned medium (CM) of OSCC cells with/without TGF- $\beta 1$. Immunohistochemistry was performed to validate proteins of CK, VIM, E-cad and Snail1 in OSCC tissue samples with bone invasion. Results showed minimal staining of VIM was found in SCC25 and HN5, while Tca8113 cells stained strongly. EMT markers Twist1 and N-cad were up-regulated; Snail1 and E-cad down-regulated
\end{abstract}

\section{J. Quan}

Schools of Dentistry, and Medical Science, Griffith Health Institute, Griffith University, Parklands Drive, Southport,

Gold Coast, QLD 4222, Australia

Present Address:

J. Quan

Guanghua School and Hospital of Stomatology, Sun Yat-sen

University, Guangzhou, People's Republic of China

M. Elhousiny · J. Gao $(\bowtie)$

School of Medicine and Dentistry, James Cook University,

PO Box 6811, Cairns, QLD 4870, Australia

e-mail: jin.gao@jcu.edu.au

\section{N. W. Johnson}

Griffith Health Institute: Population and Social Health Research Group; Molecular Basis of Disease Research Group, Gold Coast Campus, Griffith University, Gold Coast, QLD 4222, Australia in all cells. Of factors associated with invasion, MMP-2 was unchanged and MMP-9 increased in SCC25 and Tca8113, while MMP-2 was increased and MMP-9 unchanged in HN5. For osteoclast-related molecules, both MT1-MMP and RANKL were up-regulated, while OPG was downregulated in all cells. CM of OSCC cells pre-treated with TGF- $\beta 1$ showed to prolong survival of osteoclasts up to 4 days. All target molecules were validated in OSCC samples of bone invasion. These findings suggest that TGF- $\beta 1$ not only induces EMT to increase the capacity of OSCC for invasion, but also promotes factors which prolong osteoclast survival. TGF- $\beta 1$ may enhance the ability of MMP2/9 in resorbing bone and favouring invasion of cancer cells.

Keywords Bone invasion - Osteoclast - Oral squamous cell carcinoma - Transforming growth factor- $\beta 1$.

Epithelial-mesenchymal transition

$\begin{array}{ll}\text { Abbreviation } & \\ \text { OSCC } & \text { Oral squamous cell carcinoma } \\ \text { EMT } & \text { Epithelial-mesenchymal transition } \\ \text { CM } & \text { Conditioned medium } \\ \text { TGF- } \beta 1 & \text { Transforming growth factor- } \beta 1 \\ \text { MMP-2 } & \text { Matrix metalloproteinase-2 } \\ \text { MMP-9 } & \text { Matrix metalloproteinase-9 } \\ \text { CK } & \text { Cytokeratin } \\ \text { VIM } & \text { Vimentin } \\ \text { E-cad } & \text { E-cadherin } \\ \text { N-cad } & \text { N-cadherin } \\ \text { MT1-MMP } & \text { Membrane type 1 matrix metalloproteinase } \\ \text { TIMP-1 } & \text { Tissue inhibitor of matrix metalloproteinase-1 } \\ \text { TIMP-2 } & \text { Tissue inhibitors of matrix metalloproteinase-2 } \\ \text { RANKL } & \text { Receptor activator of nuclear factor (NF)- } \kappa B \\ & \text { ligand }\end{array}$


OPG Osteoprotegerin

TRAP Tartrate-resistant acid phosphatase

\section{Introduction}

Bone invasion is one of the most frequent complications of OSCC, especially those arising in the retromolar trigone, buccal sulci, gingiva, floor of mouth and hard palate. The incidence is as high as $56 \%$ of investigated patients $[1,2]$. Bone involvement contributes to increased morbidity, higher recurrence and mortality rates [3,4]. Despite improvements in current treatment modalities-surgery, radiotherapy and adjunctive chemotherapy, cure rates for these patients remain low. Fortunately, there have been considerable advances in understanding the molecular mechanisms of the process of neoplasia, so that the possibility of individualised biotherapies is increasingly recognised. Understanding and interfering with molecules involved in bone invasion may enhance such therapeutic options [5].

When epithelial neoplasms metastasise to bone, a vicious circle is established between the malignant cells themselves, and bone tissue. This also occurs when carcinoma invades bone directly, such as with oral cancer [6]. On the one hand, tumour cells secrete multiple factors to alter the bone environment and induce the formation of osteoclasts; while on the other hand, osteoclasts release growth factors from the bone matrix, which then stimulate tumour growth and further accelerate bone destruction $[7,8]$. Of these, TGF- $\beta 1$, which has been widely studied, is a major bone-derived factor responsible for driving this vicious circle. TGF- $\beta 1$, along with activins, inhibins, and bone morphogenetic proteins (BMP), are members of the TGF- $\beta$ super family $[9,10]$. For cancer cells, TGF- $\beta 1$ can become an oncogenic factor to induce proliferation, invasion and immunosuppression during tumour progression $[11,12]$ and is implicated in bone metastasis from several solid tumours. Mohammad et al. showed that the inhibitor of TGF- $\beta$ receptor I (T $\beta R I)$ kinase, effectively reduced osteolytic lesions and tumour burden in mice with malignant melanoma [13]. Ganapathy et al. demonstrated that two types of TGF- $\beta$ pathway antagonists (1D11 and LY2109761) significantly decreased metastasis to lung and bone of nude mice, injected with cells of human basal-like breast cancer [14]. As for bone invasion by OSCC, a recent study found that T $\beta R I$ was expressed by 18 of 21 patients with gingival SC, and the inhibitor of T $\beta R I$ greatly reduced the bone destruction caused by OSCC cells in vitro [15]. Additionally, Prime et al. [16] observed that the OSCC cell lines, which were resistant to inhibitory effects of TGF- $\beta 1$, formed significantly more primary tumours, with high incidence of mandibular invasion, when injected through the floor of the mouth of athymic mice.
In the present study, we found that conditioned medium (CM) of osteoblasts induced gene expression level changes of OSCC cells [17], for example, Twist1, was up-regulated in these cells after such treatment. The expression of MMP-2 protein level was increased, while MMP-9 was decreased. Furthermore, immunohistochemical staining of Twist1, MMP-2 and MMP-9 was observed in clinical samples of OSCC patients with bone invasion. We speculate that these changes in gene expression may be caused by growth factors in the CM. Since TGF- $\beta 1$ was present in significant amounts in the bone microenvironment, and proven to induce EMT in various epithelial cells in vitro [12], we attempted to determine the effects of TGF- $\beta 1$ on OSCC cells and the way they interact with osteoclasts.

\section{Materials and methods}

Reagents and antibodies

Recombinant TGF- $\beta 1$ was purchased from R\&D Systems (Minneapolis, USA). DMEM, foetal bovine serum (FBS), trypsin-EDTA, anti-CK (anti-pan cytokeratin), anti-VIM and anti-E-cad were purchased from Invitrogen. AntiTwist1, anti-Snail1, anti-MT1-MMP, anti-tissue inhibitors of MMP (TIMP1), anti-TIMP2 and anti-OPG were bought from Santa Cruz Biotechnology; while anti-RANKL and anti- $\alpha$-Tubulin were from Abcam. Anti-N-cad was purchased from Cell Signalling. Primary antibodies were either mouse or rabbit against human. Secondary antibodies, goat anti-mouse IgG and goat anti-rabbit $\operatorname{IgG}$, were from Bio-Rad Laboratories.

\section{Indirect co-cultures}

OSCC cell lines of SCC25, HN5 and Tca8113 were kindly supplied by Associate Professor Nick Saunders (The University of Queensland, Australia), Professor Ming Wei (Griffith University, Australia) and Professor Qian Tao (Sun Yat-sen University, China) respectively. These cells were routinely maintained in DMEM containing $10 \%$ FBS. Human foetal osteoblasts (hFOB) were obtained from American Type Tissue Collection (ATCC, Rockville, USA), and grown in DMEM/F12 with $10 \%$ FBS plus $300 \mu \mathrm{g} / \mathrm{mL}$ geneticin (G418) at $34{ }^{\circ} \mathrm{C}$ in an incubator. CM [17] was collected from OSCC cell lines SCC15 and SCC25, and from $\mathrm{hFOB}$, and used for indirect co-culture: OSCC cells were treated with $\mathrm{CM}$ of $\mathrm{hFOB}$ cells for $48 \mathrm{hs}$. To block the endogenous TGF- $\beta 1$ secreted by hFOB cells, TGF- $\beta$ inhibitor (SB431542, $188 \mathrm{nM}$, Sigma) was used in CM of $\mathrm{hFOB}$ to treat OSCC cells for $48 \mathrm{~h}$. To examine the effects of TGF- $\beta 1$ on OSCC cells, equal numbers of SCC $25, \mathrm{HN} 5$ and Tca8113 cells were plated in serum-free medium, starved for 
$12 \mathrm{~h}$, and then treated with TGF- $\beta 1(5 \mathrm{ng} / \mathrm{mL})$ for 0 , 1-3 days. Culture medium was changed daily.

Immunocytochemistry

After the treatment with TGF- $\beta 1$ for $0-3$ days, OSCC cells were fixed with $70 \%$ ethanol for $10 \mathrm{~min}$ and permeabilized by $0.1 \%$ Triton X-100 for 5 min. Non-specific binding of the antibodies was avoided by blocking with $5 \%$ BSA in PBS for $30 \mathrm{~min}$, followed by incubation with primary antibodies of CK (1:50) and VIM (1:50) overnight at $4{ }^{\circ} \mathrm{C}$, and then with secondary antibodies for $1 \mathrm{~h}$ at $37^{\circ} \mathrm{C}$. Nonimmune serum instead of the primary antibody was used as negative controls. Three washes with PBS were applied between each step of antibody incubation. Sites of binding were visualized using liquid diaminobenzidine (DAB) + substrate + chromogen system (DAKO), counterstained with Mayer's haematoxylin, and photographed by a Nikon OXM1200 digital camera with the Act-1 program. Immunostaining intensity was scored according to percentage of tumour cells with positively-stained: designated as + where $<20 \%$ of cells were stained; ++ where $<40 \%$ were stained; +++ where $>60 \%$ were stained.

\section{Real-time PCR}

Total RNA was isolated from OSCC cells before and after TGF- $\beta 1$ treatment using the PureLink RNA Mini Kit (Invitrogen, USA), and reverse transcribed to cDNA using the iScript cDNA Synthesis Kit (Bio-Rad) based on the manufacturer's instructions. Quantitative gene analysis was performed for Twist1, Snail1, E-cad, N-cad, MMP-2, MMP-9, TIMP-1, TIMP-2, MT1-MMP, RANKL and OPG by using EXPRESS SYBR GreenER qPCR Supermix Universal Kit (Invitrogen, USA) and the icycler iQ5 Realtime PCR system (Bio-Rad, USA). The data were normalized to the internal control, GAPDH to obtain $\Delta \mathrm{Ct}$. Finally fold-change of genes of interest relative to untreated samples was reported by $2^{-\Delta \Delta \mathrm{Ct}}$ method. Primers used in this study are listed in Table 1 .

\section{Gelatine zymography}

Equal numbers of OSCC cells of SCC25, HN5, and Tca8113 were planted in 6-well plates with the density of $10^{6}$ cells per well. CM from OSCC cells before and after TGF- $\beta 1$ treatment was used for Gelatine Zymography. CM of HT 1,080 cells served as the positive control. $20 \mu \mathrm{L}$ of each sample was mixed with non-reducing sample buffer (62.5 mM Tris- $\mathrm{HCl}, \mathrm{pH}$ 6.8; $4 \%$ SDS; $25 \%$ glycerol; $0.01 \%$ Bromophenol Blue) and electrophoresed on $10 \%$ precast denaturing SDS polyacrylamide gels with gelatine (Bio-Rad Lab, CA, USA). Gels were washed in the commercial renature solution $(2.5 \%$ Triton $\mathrm{X}-100)$ for $40 \mathrm{~min}$ at room temperature and incubated in development solution $\left(50 \mathrm{mM}\right.$ Tris; $200 \mathrm{mM} \mathrm{NaCl} ; 5 \mathrm{mM} \mathrm{CaCl}{ }_{2}$; $0.02 \%$ Brij-35) at $37{ }^{\circ} \mathrm{C}$ for $40 \mathrm{~h}$. Finally, gels were stained with Coomassie Brilliant Blue R-250 (Sigma, USA) for $1 \mathrm{~h}$ at room temperature and progressively destained until clear bands appeared against the blue background.

\section{Western blotting}

Total protein was extracted from OSCC cells before and after TGF- $\beta 1$ treatment using lysis buffer (Thermo scientific, USA). The protein concentration was determined using a BCA Protein Assay Kit (PIERCE, USA). $40 \mu \mathrm{g}$ of protein was subjected to SDS-PAGE with $10 \%$ polyacrylamide gels. Proteins were transferred to PVDF membranes, and blocked with $5 \%$ non-fat dry milk in Trisbuffered saline (TBS) for $1 \mathrm{~h}$ at room temperature. The membranes were then incubated with primary antibodies of Twist1 (1:200), Snail1 (1:200), E-cad (1:200), N-cad (1:100), TIMP-1 and TIMP-2 (1:200), MT1-MMP (1:200), RANKL (1:500), OPG (1:200) and $\alpha$-Tubulin $(1: 3,000)$ overnight at $4{ }^{\circ} \mathrm{C}$, washed twice and incubated with horseradish peroxidase-conjugated (HRP) secondary antibodies for $1 \mathrm{~h}$ at room temperature. The protein bands were detected by SuperSignal WestPico Chemiluminescent Substrate (Thermo scientific) and visualised using the VersaDoc-MP Imaging Systems (Bio-Rad).

Osteoclasts differentiation from RAW264.7 cells

Mature osteoclasts were generated from the murine macrophage cell line of RAW264.7, which was kindly given by Dr Stephen Hamlet (Griffith University). RAW264.7 cells were cultured in DMEM with $10 \%$ FBS at $37^{\circ} \mathrm{C}$ in a humidified $5 \% \mathrm{CO}_{2}$ atmosphere. To obtain osteoclasts, these cells were seeded in a 96-well plate at a density of $1.25 \times 10^{4}$ cells/well, and supplemented with $50 \mathrm{ng} / \mathrm{mL}$ of recombinant mouse RANKL (R\&D Syetems, USA) on day 1 and day 3. Mature osteoclasts were observed on day 5. Afterwards, the entire culture medium was changed into $\mathrm{CM}$ of OSCC cells pre-treated with or without TGF- $\beta 1(5 \mathrm{ng} / \mathrm{mL})$. After 4 days' treatment, TRAP staining (STrACP, Nanjing Jiancheng, China) was performed and photographed using a Nikon OXM1200 digital camera with the Act-1 program.

Validation of EMT related markers in clinical samples

To validate proteins of CK, VIM, E-cad and Snail1, the archival blocks from 12 patients whose OSCC showed 
Table 1 Primer Sequences Used in Real-time PCR

\begin{tabular}{|c|c|c|}
\hline Genes & Primers & $\begin{array}{l}\text { Length } \\
\text { (bp) }\end{array}$ \\
\hline Twist1 & $\begin{array}{l}\text { Forward: 5'-TGTCCGCGTCCCACTAGC-3' } \\
\text { Reverse: 5'- } \\
\text { TGTCCATTTTCTCCTTCTCTGGA-3' }\end{array}$ & 63 \\
\hline Snail1 & $\begin{array}{l}\text { Forward: } 5^{\prime}- \\
\text { TGCAGGACTCTAATCCAAGTTTACC-3' } \\
\text { Reverse: } 5^{\prime} \text {-GTGGGATGGCTGCCAGC-3' }\end{array}$ & 71 \\
\hline E-cad & $\begin{array}{l}\text { Forward: } 5^{\prime}- \\
\text { GAACAGCACGTACACAGCCCT-3' } \\
\text { Reverse: } 5^{\prime}- \\
\text { GCAGAAGTGTCCCTGTTCCAG-3' }\end{array}$ & 76 \\
\hline N-cad & $\begin{array}{l}\text { Forward: 5'- GACGGTTCGCCATCCAGAC-3' } \\
\text { Reverse: } 5^{\prime} \text {-TCGATTGGTTTGACCACGG-3' }\end{array}$ & 66 \\
\hline MMP-2 & $\begin{array}{l}\text { Forward: 5'- } \\
\text { GACATACATCTTTGCTGGAGAC-3' } \\
\text { Reverse: 5'-TTCAGGTAATAGGCACCCTT- } \\
3^{\prime}\end{array}$ & 180 \\
\hline MMP-9 & $\begin{array}{l}\text { Forward: } 5^{\prime} \text {-CTTCACTTTCCTGGGTAAG } \\
\text { G-3' } \\
\text { Reverse: 5'-CACTTCTTGTCGCTGTCAAA-3' }\end{array}$ & 105 \\
\hline TIMP-1 & $\begin{array}{l}\text { Forward: 5'- } \\
\text { GGAGAGTGTCTGCGGATACTTC-3' } \\
\text { Reverse: } 5^{\prime}- \\
\text { GCAGGTAGTGATGTGCAAGAGTC-3' }\end{array}$ & 100 \\
\hline TIMP-2 & $\begin{array}{l}\text { Forward: 5'- } \\
\text { ACCCTCTGTGACTTCATCGTGC-3' } \\
\text { Reverse: } 5^{\prime}- \\
\text { GGAGATGTAGCACGGGATCATG-3' }\end{array}$ & 129 \\
\hline $\begin{array}{l}\text { MT1- } \\
\text { MMP }\end{array}$ & $\begin{array}{l}\text { Forward: } 5^{\prime}- \\
\text { CCTTGGACTGTCAGGAATGAGG-3' } \\
\text { Reverse: } 5^{\prime}- \\
\text { TTCTCCGTGTCCATCCACTGGT-3' }\end{array}$ & 146 \\
\hline RANKL & $\begin{array}{l}\text { Forward: } 5^{\prime}- \\
\text { CAGAAGATGGCACTCACTGCA-3' } \\
\text { Reverse: } 5^{\prime} \text {-CACCATCGCTTTCTCTGCTCT- } \\
3^{\prime}\end{array}$ & 203 \\
\hline OPG & $\begin{array}{l}\text { Forward: 5'- } \\
\text { GGAACCCCAGAGCGAAATACA-3' } \\
\text { Reverse: } 5^{\prime}- \\
\text { CCTGAAGAATGCCTCCTCACA-3' }\end{array}$ & 225 \\
\hline GAPDH & $\begin{array}{l}\text { Forward: 5'-TGCACCACCAACTGCTTAGC- } \\
3^{\prime} \\
\text { Reverse: } 5^{\prime}- \\
\text { GGCATGGACTGTGGTCATGAG-3' }\end{array}$ & 87 \\
\hline
\end{tabular}

invasion of bone were randomly examined. The Human Research Ethical Clearance was granted by both Griffith University and Queensland Health prior to the commencement of the study. Serial tissue sections $(5 \mu \mathrm{m}$ thickness) were dewaxed, rehydrated and treated with $0.3 \%$ hydrogen peroxide in PBS. Antigen retrieval was performed in $0.2 \%$ citrate buffer $(\mathrm{pH}$ 6.0) by heating sections in a microwave oven $(2 \times 4 \mathrm{~min})$. After nonspecific binding was blocked with $5 \%$ BSA in PBS for $30 \mathrm{~min}$, sections were incubated with primary antibodies of CK (1:50), VIM (1:50), E-cad (1:80) and Snail1 (1:100) overnight at $4{ }^{\circ} \mathrm{C}$. Sections were then treated with the antimouse/rabbit secondary antibodies (Envision + Systems) for $30 \mathrm{~min}$, followed by DAB detection solution (Dako, Botany, Australia) for a few minutes at room temperature. Primary antibodies were replaced by non-immune serum as negative controls. Sections were counterstained with Mayer's haematoxylin, dehydrated, and mounted with DPX (BDH Laboratory, Poole, England). The final results were visualized by a light microscopy and photographed using an Olympus Bx60 digital camera with the CellSens software.

Statistical analysis

Data analysis was performed using SAS program (SAS version 8.1, USA). A paired Student $t$ test was used to compare two means. A $p$ value of less than 0.05 was regarded as significant.

\section{Results}

Indirect co-cultures between osteoblasts and OSCC cells

Results showed that Twist 1 expression was up-regulated in OSCC cells after the treatment with $\mathrm{CM}$ from cells of hFOB. MMP-2 was increased while MMP-9 was decreased in all OSCC cells. To verify the effect of TGF-b secreted by hFOB in the co-cultures, hFOB was pretreated with the inhibitor of TGF-b (SB431542) followed by the co-culture. It was found the reduction of expressions of Twist-1 and MMP-2, but slightly increased MMP-9, which suggested bioefficiency of the inhibitor (Fig. 1a). Immunochemical staining of these molecules was observed in 12 clinical samples of OSCCC patients with bone invasion (Fig. 1b): H\&E staining showed an infiltrative pattern of bone invasion with tumour cells invading into the bone, and osteoclasts accumulated in resorption lacunae. Faint staining of Twist 1 was noted in the cytoplasm of OSCC cells, but strongly in osteoclasts. MMP-2 was weakly expressed in OSCC cells and osteoclasts, while MMP-9 was clearly localized within the cytoplasm of OSCC cells and especially in the nuclei of osteoclasts.

The cell morphology of OSCC remained no change, neither was in the staining intensity of cytokeratin changed (Fig. 2a). A summary of the staining results is shown in 

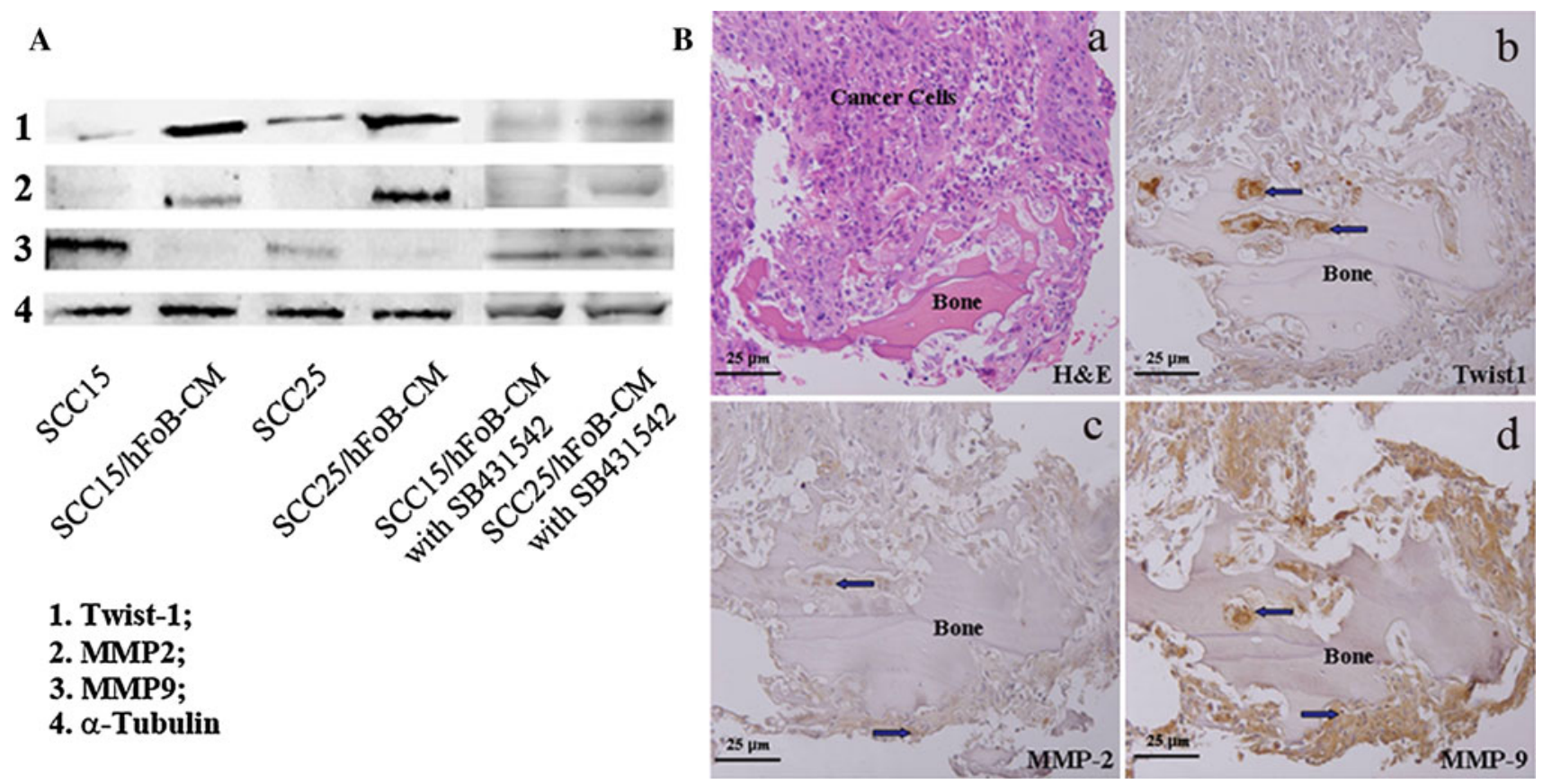

\section{Twist-1; \\ 2. MMP2; \\ 3. MMP9; \\ 4. $\alpha$-Tubulin}

Fig. 1 Results of the indirect co-culture between hFOB and OSCC cells. a Western blotting shows that Twist 1 expression is up-regulated after the treatment with $\mathrm{CM}$ from $\mathrm{hFOB}$ cells. The expression of MMP-2 is increased, while MMP-9 decreases in all OSCC cells. Expression of Twist-1, MMP-2 by OSCC cells was reduced, while MMP-9 was increased after the blockage of TGF- $\beta 1$ by using SB431542. b H\&E staining shows an infiltrative pattern of bone

Fig. 2b. However, weak staining of VIM was found in SCC25 and HN5 following the treatments with TGF- $\beta 1$. Same staining of VIM was also found in Tca8113 cells before and after the treatments (Fig. 2b).

mRNA level changes of selected genes after treatment with TGF- $\beta 1$

Real-time PCR was utilized to examine mRNA levels of selected genes. The EMT markers, Twist 1 and N-cad, were shown to have increased expression, while Snaill and E-cad were down-regulated in all cells after treatment with TGF- $\beta 1$ (Fig. 3a-c). The cell invasion factor MMP-2 was not affected in SCC25 and Tca8113 cells, while it was induced in HN5 cells. Conversely, MMP-9 was un-affected in HN5, but was up-regulated in SCC25 and Tca8113 cells. Furthermore, TIMP-1 was decreased in SCC25 and Tca8113 cells, while the expression of HN5 was increased. TIMP-2 was induced in SCC25 and Tca8113, but suppressed in HN5 cells. For osteoclast-related molecules, the expression of both MT1-MMP and RANKL was increased, but OPG was suppressed in all cells. invasion with osteoclasts accumulating in resorption lacunae (a). Weak immunohistochemical staining of Twist1 shows in the cytoplasm of OSCC cells, but strongly stained in osteoclasts (b). MMP-2 is weakly expressed in OSCC cells and osteoclasts (c), while MMP-9 is clearly localized within the cytoplasm of OSCC cells, especially in the nuclei of osteoclasts (d)

Changes of zymogenic activity of MMP-2 and MMP-9 after treatments with TGF- $\beta 1$

Zymography was used to detect the zymogenic activities of MMP-2/-9 (Fig. 4a). Results showed that TGF- $\beta 1$ increased the activities of MMP-9 in SCC25 and Tca8113 cells, and the activities of MMP-2 in HN5 cells (Fig. 4b).

Expression of protein changes of targeted genes after treatment with TGF- $\beta 1$

Western blotting was performed to validate expressions of TGF- $\beta 1$ targeted genes at the protein level. Comparing with results of real-time PCR, the expression pattern was almost the same with a few differences (Fig. 5a-c). For EMT markers, Twist1 was increased while Snaill was decreased in all OSCC cells. E-cad was slightly suppressed in $\mathrm{SCC} 25$ cells while it was dramatically suppressed in HN5 cells, but not detected in Tca8113 cells. N-cad was found to be induced in all cells tested. TIMP-1 was downregulated and TIMP-2 was un-changed in both SCC25 and Tca8113 cells; while TIMP-1 was un-affected and TIMP-2 was suppressed in HN5 cells. For osteoclast-related 


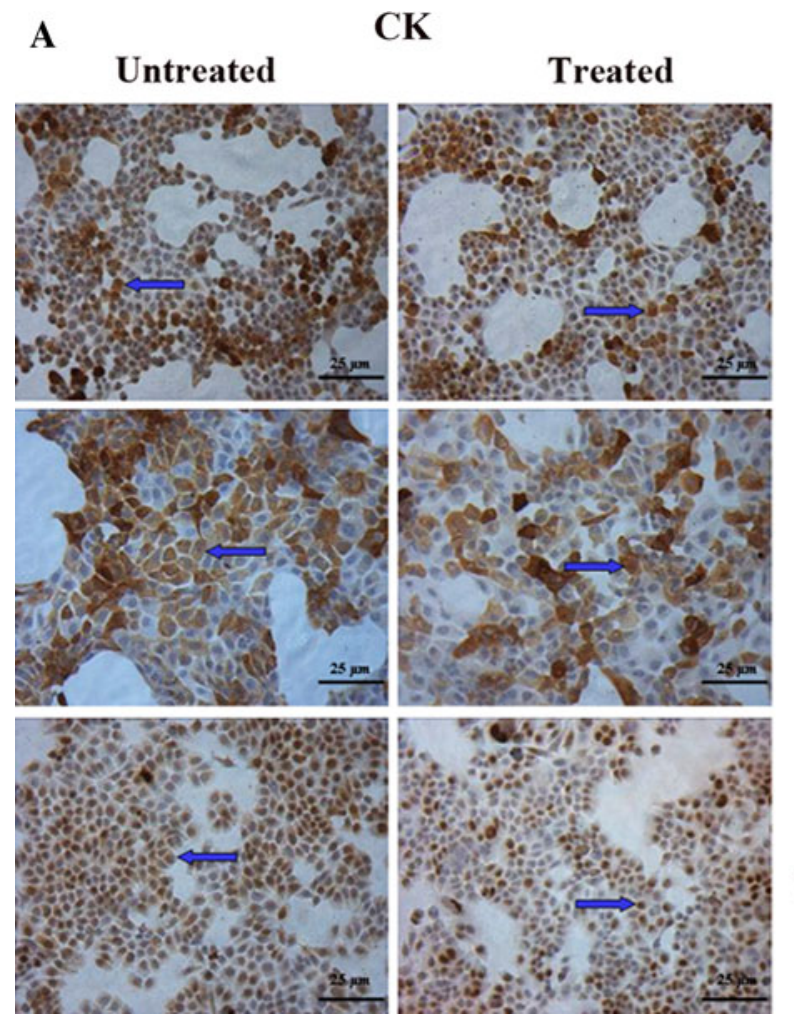

Fig. 2 Immunohistochemical staining of $\mathrm{CK}$ and VIM in OSCC cells. a Similar staining patterns are visualised at each time point: $\mathrm{CK}$ staining has no change in the epithelial OSCC cells (arrows, bar $=25 \mu \mathrm{m}$ ); weak staining of VIM is shown in SCC25 and HN5,

molecules, MT1-MMP was up-regulated in all cells. Furthermore, RANKL was induced in SCC25 and Tca8113 cells, while it was not detected in HN5 cells. Expressions of OPG were decreased in all OSCC cells.

$\mathrm{CM}$ of OSCC cells treated with TGF- $\beta 1$ prolonged the survival of mature osteoclasts

Mature osteoclasts generated from the murine macrophage cell line, RAW264.7, were treated with CM of OSCC cells with or without TGF- $\beta 1$. Since our earlier results had shown significant changes of EMT markers on days 1 and 2 , CM of OSCC cells were here treated with TGF- $\beta 1$ for 24 or $48 \mathrm{~h}$. Similar results were observed on each day as follows: comparing with $\mathrm{CM}$ from OSCC cells without TGF- $\beta 1$, CM from OSCC cells pre-treated with TGF- $\beta 1$ prolonged the survival of osteoclasts up to 4 days (Fig. 6a-b). Osteoclasts with continual RANKL treatment became apoptotic on day 4 , TGF- $\beta 1(5 \mathrm{ng} / \mathrm{mL})$ also induced the apoptosis of mature osteoclasts on day 4 (Fig. 6a-b).
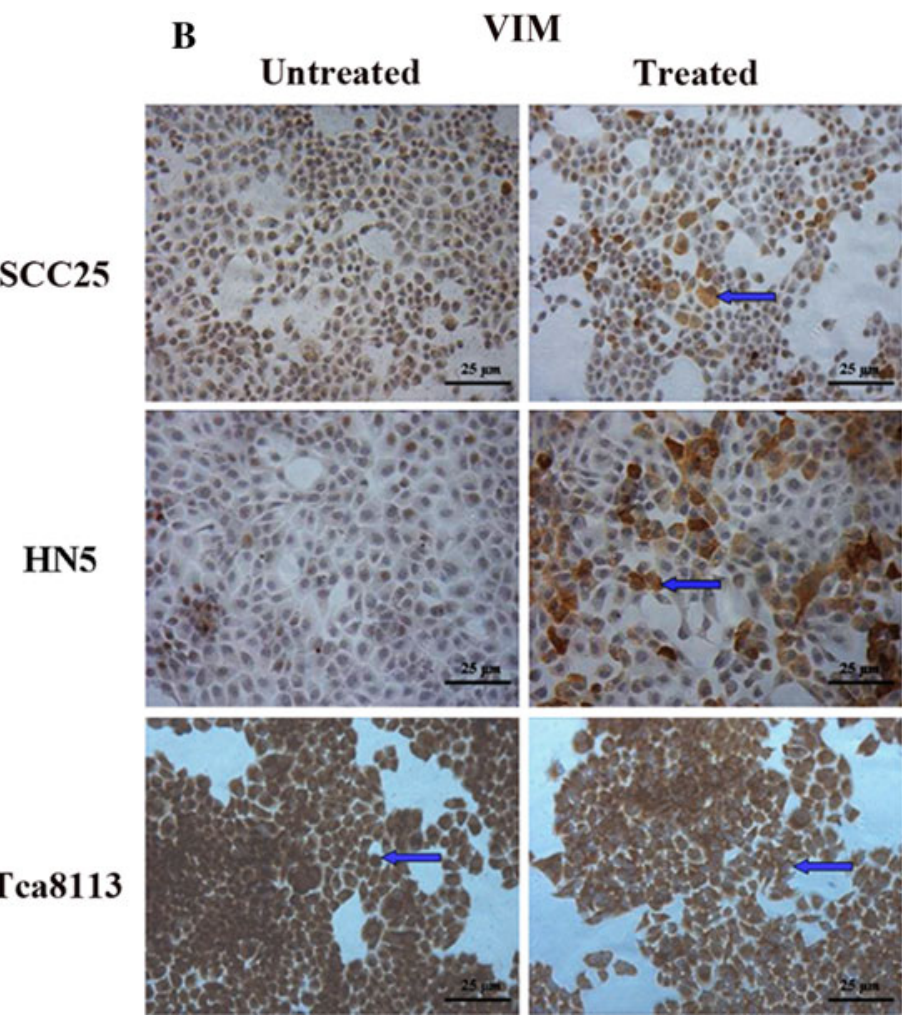

while VIM is strongly stained in Tca8113 cells before and after the treatment (arrows, bar $=25 \mu \mathrm{m})$. Results represent three independent experiments. b Summary of the immunohistochemical staining results

Validation of targeted molecules in human OSCC tissues with bone invasion

The H\&E staining on archived OSCC tissue sections obtained from 12 patients with bone invasion showed an infiltrative pattern, and cancer cells invaded into the bone tissue (Fig. 7a). Using immunohistochemistry, it was found that CK was strongly expressed in the cytoplasm of OSCC cells, while VIM was weakly stained within the cytoplasm of OSCC cells (Fig. 7b-c). For E-cad, weak cytoplasmic expression was found in OSCC cells (Fig. 7d). Stronger cytoplasmic expression of Snaill was observed in cytoplasm of OSCC cells (Fig. 7e). Control sections were negatively stained (Fig. 7f).

\section{Discussion}

TGF- $\beta$ is well known to be a key initiator of EMT, which can induce artificial EMT of normal epithelial cells as well as of malignant cells $[12,18]$. In our present study, we 
Fig. 3 Real-time PCR in three OSCC cell lines (a SCC25, b HN5, c Tca8113) before and after treatments with TGF- $\beta 1$. The expression of EMT markers, Twist1 and N-cad, are shown to have increased expression, while Snaill and E-cad are down-regulated in all types of cells following the treatments with TGF- $\beta 1$. The cell invasion factor, MMP-2, is not affected in SCC25 and Tca8113 cells, but the expression of MMP-2 is induced in HN5 cells. Conversely, MMP-9 is not affected in HN5 cells, while it is up-regulated in SCC25 and Tca8113 cells.

Moreover, TIMP-1 is suppressed in SCC25 and Tca8113 cells, while the expression of HN5 cells is increased. On the other hand, TIMP-2 is induced in SCC25 and Tca8113 cells, but is suppressed in HN5 cells. For osteoclast-related molecules, both MT1-MMP and RANKL are induced while OPG is suppressed in all cells tested. Data are shown as mean \pm SD of three independent experiments
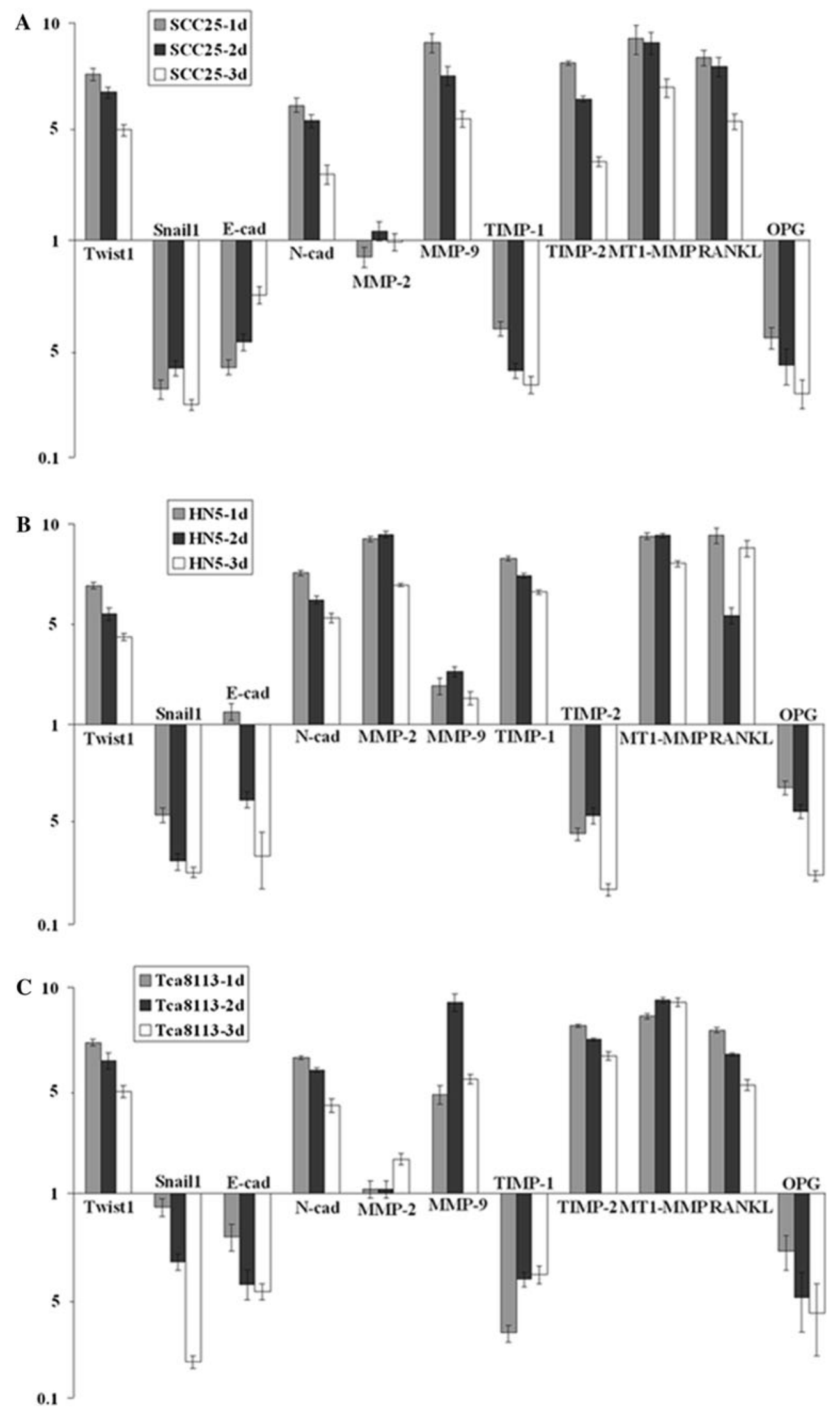

OSCC cells before and after treatment with TGF- $\beta 1$. a TGF$\beta 1$ mediates the activities of MMP-9 in both SCC25 and Tca 8113 cells, while the activity of MMP-2 is also increased in HN5 cells. b The intensity of bands shown in the zymograph is converted to the figure using

histodensitometry analysis. The results are averaged in three independent experiments
Fig. 4 Gelatin Zymography in semi-quantitative

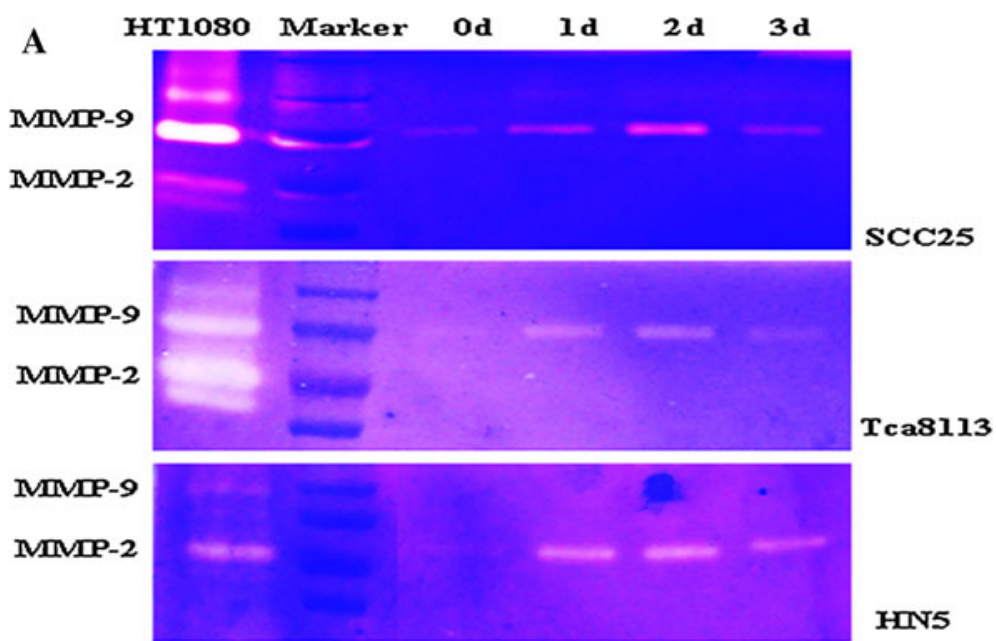

Relative expressions of MMP-9/2

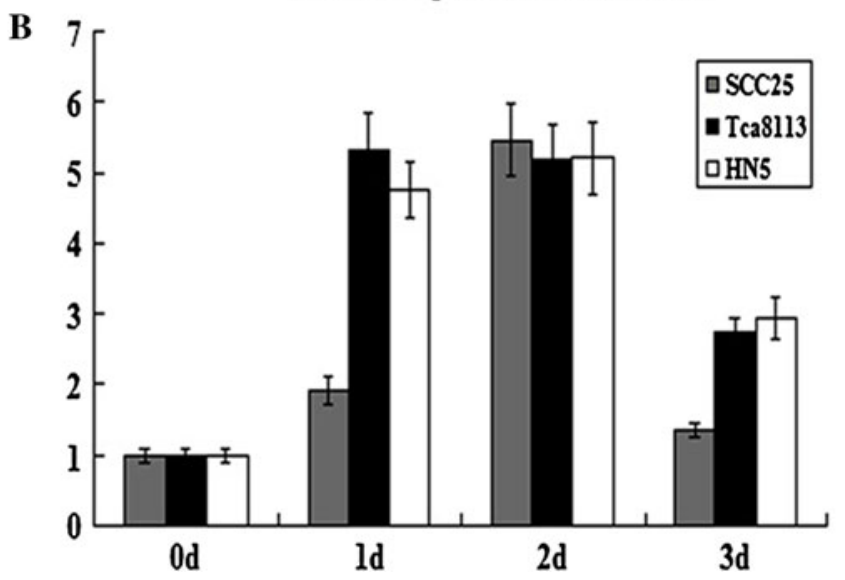

A

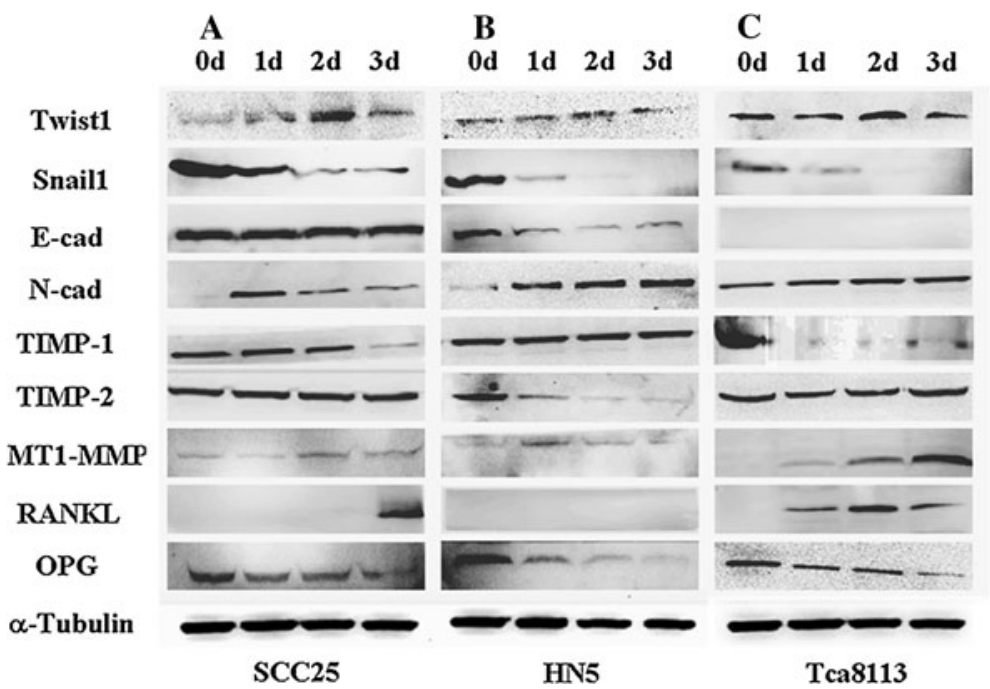

Fig. 5 Western blotting analysis of three OSCC cell lines (a SCC25, b HN5, c Tca8113) before and after treatment with TGF- $\beta 1$. For EMT markers, Twist 1 expression is increased while Snail1 is decreased in all these cells. E-cad is slightly suppressed in SCC25 while it is dramatically suppressed in HN5, and not detected in Tca8113 cells. However, expression of $\mathrm{N}-\mathrm{Cad}$ demonstrates to be switched on in all types of OSCC cells. TIMP-1 is down-regulated, but TIMP-2 has no change in both SCC25 and Tca8113 cells. While TIMP-1 is not affected, TIMP-2 is suppressed in HN5 cells. For osteoclast-related molecules, MT1-MMP is up-regulated in all OSCC cells. RANKL is induced in SCC25 and Tca8113 cells, while it is not detected in HN5 cells. Expressions of OPG are decreased in all OSCC cells. These results are representative of three independent experiments 


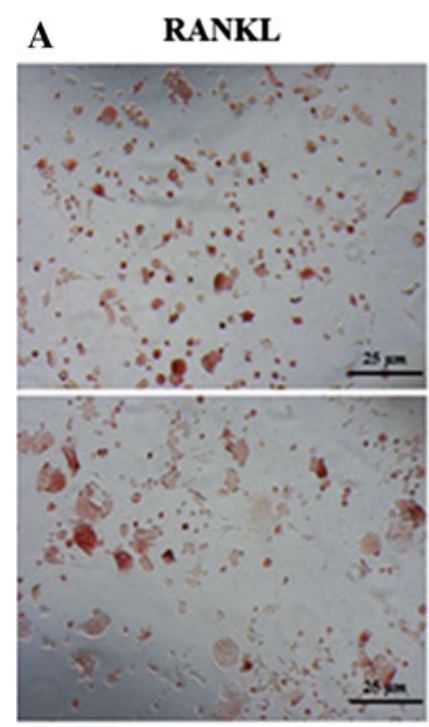

$\mathrm{CM}$ of SCC25

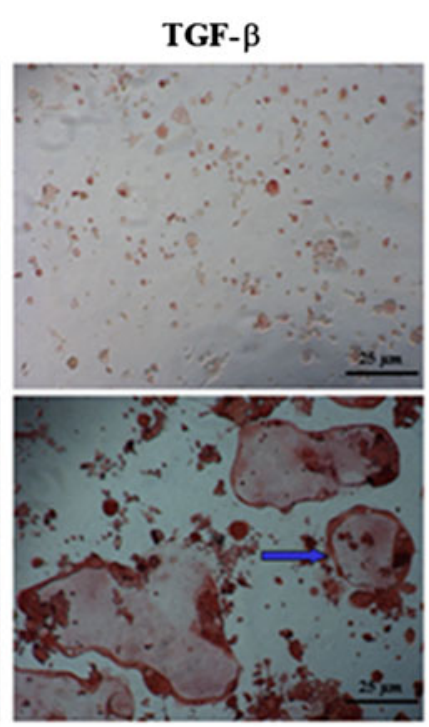

CM of SCC25 with TGF- $\beta$

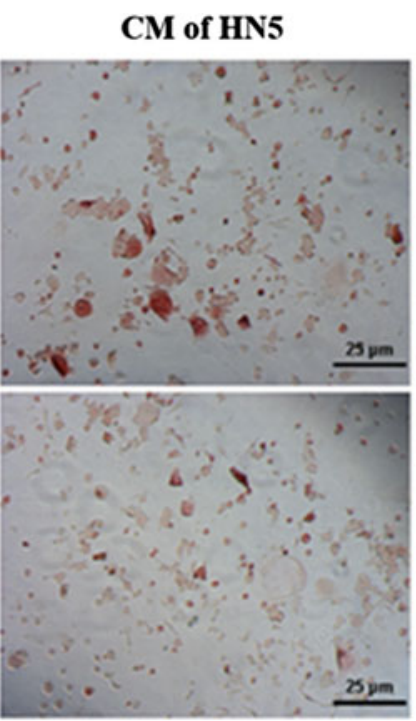

$\mathrm{CM}$ of Tca8113
CM of HN5 withTGF- $\beta$

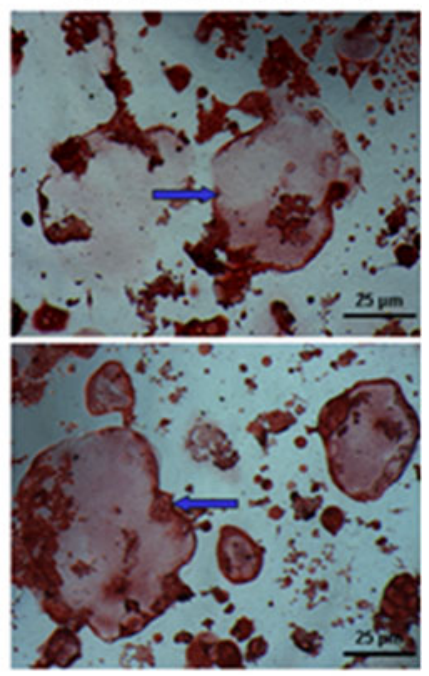

CM of Tca8113 with TGF- $\beta$

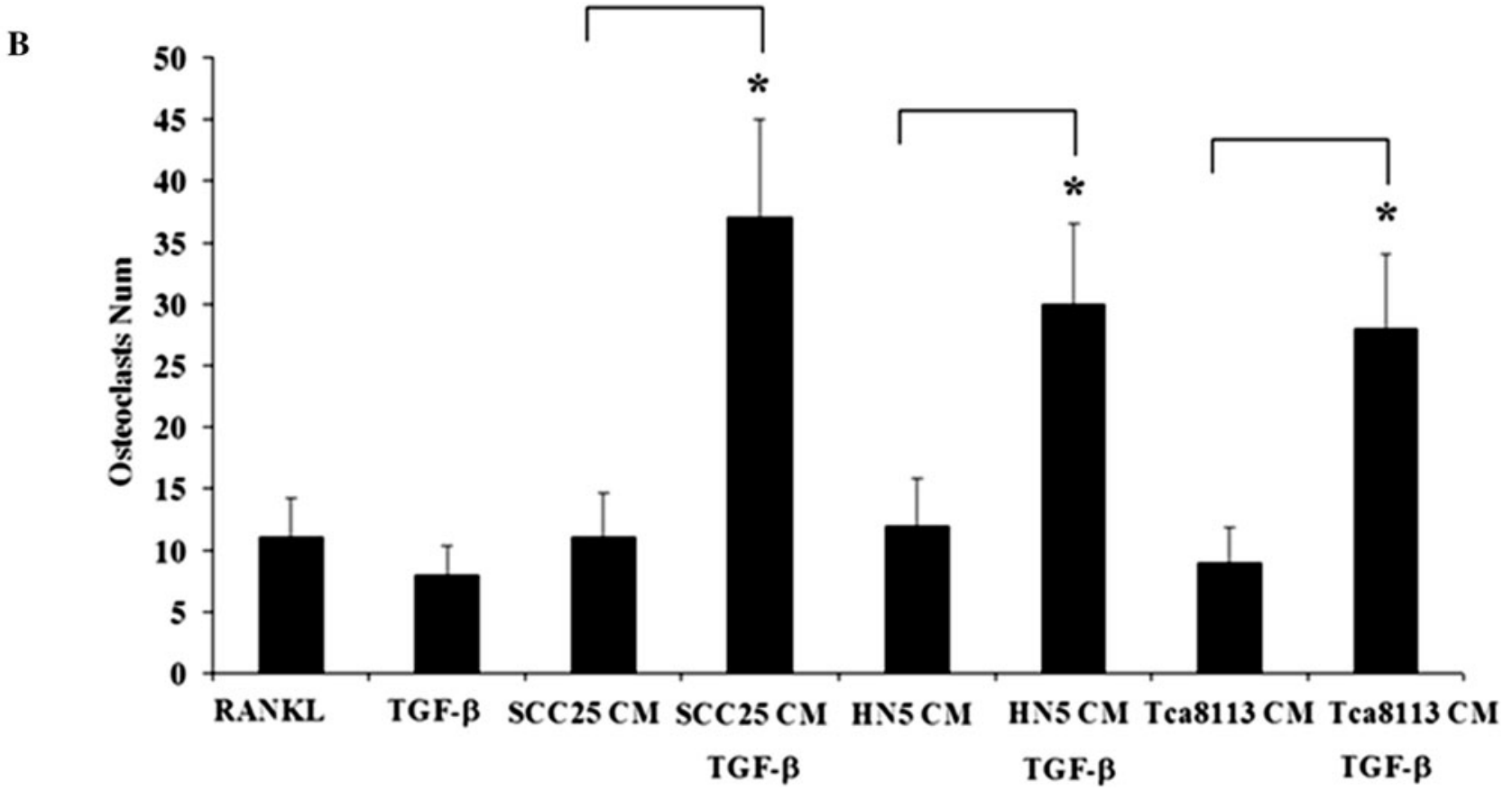

Fig. 6 TRAP staining of the mature osteoclasts generated from Raw264.7 cells. a The positive control group of osteoclasts (with continual RANKL treatment) become apoptotic on day 4 (TRAP, $b a r=25 \mu \mathrm{m})$. TGF- $\beta 1(5 \mathrm{ng} / \mathrm{mL})$ also directly induces the apoptosis of mature osteoclasts on day 4 (TRAP, bar $=25 \mu \mathrm{m}$ ). Comparing

observed that cell morphology in these OSCC cells cultures was not changed, most cells remaining polygonal during 3 days' treatment with TGF- $\beta 1$. This is consistent with our earlier studies in which morphological evidence of EMT took several days longer to become manifest [19]. For these EMT markers, typical "cadherin switching", a term referring to the ability of E-cad expression and activity to switch on the expression of $\mathrm{N}$-cad [20], was shown in all with CM of OSCC cells without TGF- $\beta 1$, CM of OSCC cells pretreated with TGF- $\beta 1$ may prolong the survival of mature osteoclasts up to 4 days (arrows, TRAP, bar $=25 \mu \mathrm{m}$ ). b Numbers of osteoclasts are counted with 4 fields randomly selected. Data are shown as $\mathrm{M} \pm \mathrm{SD}$ of three independent experiments $(*, p<0.05)$

cell lines tested. Twist1 expression was increased while Snail1 was decreased in all cells after being treated with TGF- $\beta 1$. Both Twist1 and Snail1 are nuclear transcription regulators of EMT which interact with each other, not always in a consistent fashion [21-23]. For example, Twist 1 was found to act upstream from Snail and induce EMT-like transformation in a mouse xenograft model with human breast cancer [21]; while a comparison of benign 

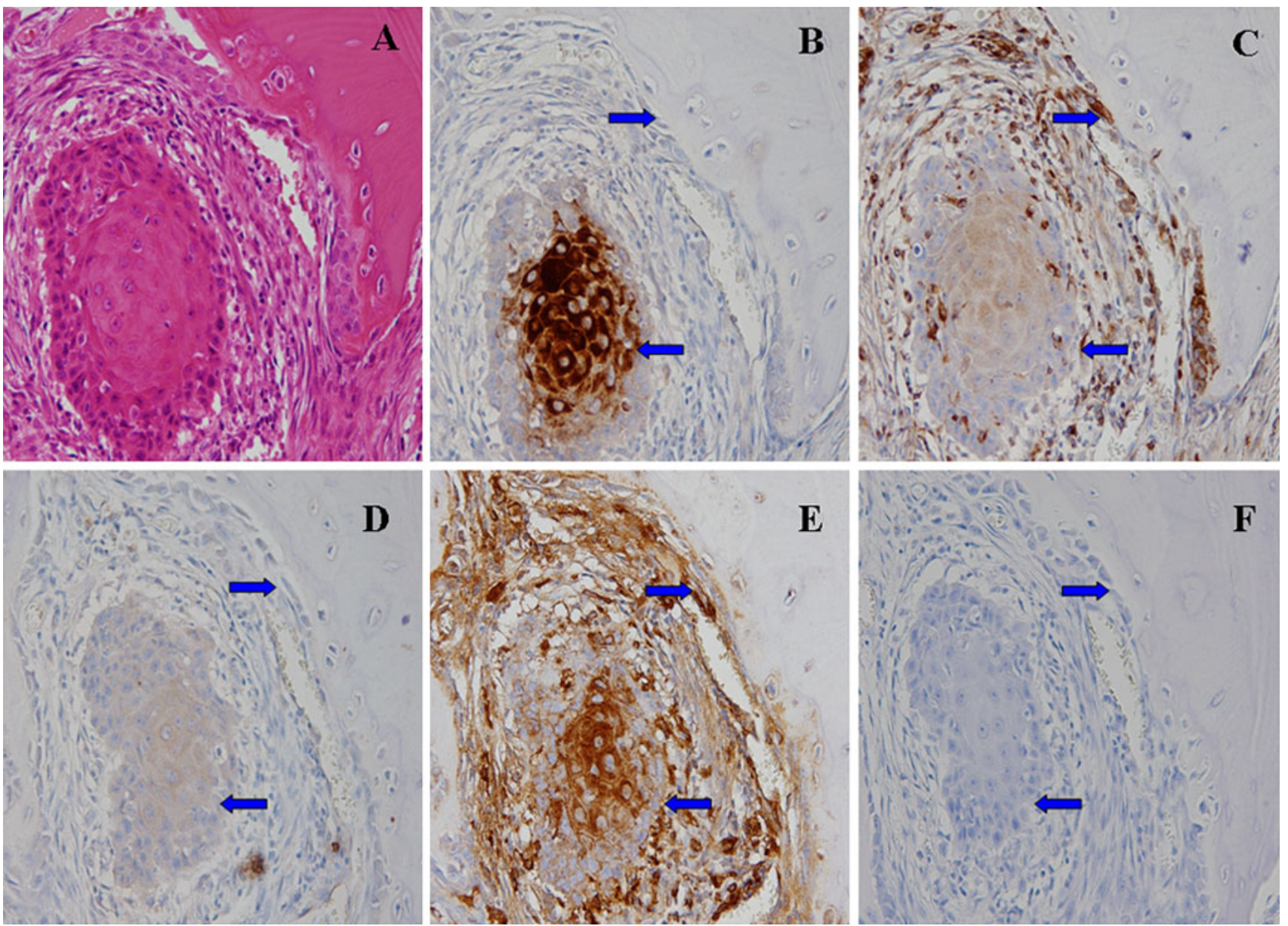

Fig. 7 Validation of targeted molecules in OSCC tissue with bone invasion using the immunohistochemical analysis. a The H\&E staining shows the infiltrative pattern of bone invasion by OSCC into the bone tissue. b Immunohistochemistry shows that $\mathrm{CK}$ is strongly expressed in the cytoplasm of OSCC cells at the centre of tumour, while weak staining is found in cancer cells at the front of bone resorption sites. $\mathbf{c}$ The VIM is weakly stained within the centre

and malignant pheochromocytoma suggested that Snail target on Twist promoting malignant transformation [22]. Whilst the reasons for these different interpretations arising in different experimental situations are currently unknown, the present study, consistent with previous co-cultures, and the increased expression of Twist 1 suggesting TGF- $\beta 1$ be the active factor in CM which initiates EMT.

The gelatinases MMP-2/-9 are associated with EMT to increase tumour invasion and metastasis [24]. We previously reported that expression of MMP-2/-9 in OSCC cells was, in relation to EMT, triggered by TGF- $\beta 1$ [19]. MMP2 and MMP- 9 are secreted but rapidly become inhibited by the specific endogenous inhibitors of TIMP-1 and TIMP-2 [25]. In the present study, TIMP-1 expression decreased and TIMP-2 increased in both SCC25 and Tca8113 cells. Conversely, MMP-2 expression was up-regulated and MMP-9 was not changed, while TIMP-1 expression was of tumour, but strongly stained in OSCC cells at the front of bone resorption sites. d Cytoplasmic expression of E-cad is weakly at the centre of tumour, but no staining in OSCC cells is shown at bone resorption sites. e The expression of Snail-1 is strongly present throughout the cytoplasm of all OSCC cells. $\mathbf{f}$ The negative control shows no staining in OSCC cells

up-regulated and TIMP-2 was down-regulated in HN5 cells. The increased expression of MMP-9 or MMP-2 in these OSCC cells suggested similar responses to TGF- $\beta$ as shown before [26, 27]. This may establish an autocrine loop: both MMP-2 and MMP-9 can mediate the cleavage of latent TGF- $\beta$ complexes [28]. Moreover, an autocrine regulation of MMP and TIMP was confirmed that endogenous MMP-9 was inhibited by TIMP-1, and TIMP-2 was the primary inhibitor of MMP-2. It is currently unknown whether this regulation is direct or indirect action of TGF$\beta$. Indeed, many signalling pathways have been involved in the regulation of TGF- $\beta$, MMP and TIMP family members, which will be explored in future studies.

Osteoclast-related factors not only include molecules which induce the formation of osteoclasts, but also those proteolytic enzymes which help to degrade the non-mineralized osteoid [29]. The gelatinases MMP-2 and MMP-9 


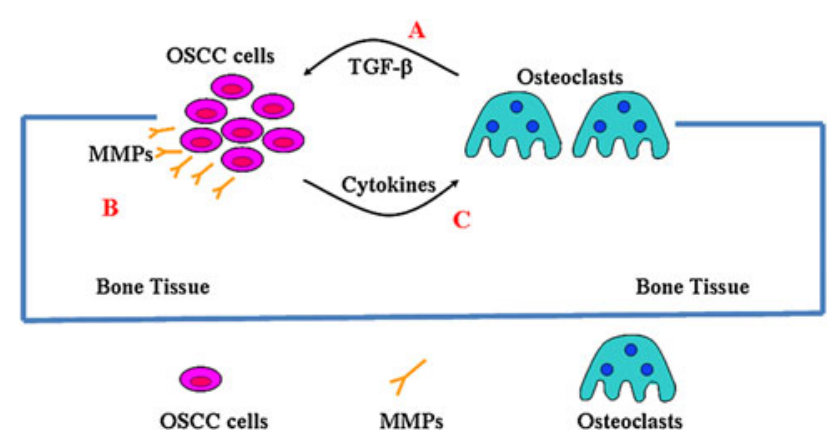

Fig. 8 Pathways involve in the progression of bone invasion by OSCC. a Osteoclasts play the main role to degrade the bone matrix, growth factors such as TGF- $\beta$ are released from the bone components. b TGF- $\beta$ may induce EMT of OSCC cells and promote expressions of MMPs, which directly facilitate invasion of cancer cells through stromal tissues or micro-cavities of bone marrow within the bone. c TGF- $\beta$ may also promote cytokines such as osteoclasts-related factors, which activate more osteoclasts and prolong their survival favouring the invasion of cancer cells

participate in the recruitment of osteoclast precursors and the differentiation of osteoclasts during the development and growth of normal tissues [30]. In addition to the gelatinase activities of MMP-2/-9, MT1-MMP functions as a sheddase, releasing non-ECM substrates such as RANKL [31]. A recent report demonstrated that MT1-MMP derived from prostate cancer cells enhanced their migration through an autocrine pathway of MT1-MMP/RANK/RANKL [32]. The present study has shown that MT1-MMP was increased in OSCC cells after being treated with TGF- $\beta 1$. To establish whether MT1-MMP has similar autocrine effects in OSCC cells as demonstrated for prostate cancer cells, we analysed the expression of RANKL and OPG and found the expression of RANKL was increased, but OPG was decreased in OSCC cells. Therefore, the suppression of OPG expression tipped the ratio of RANKL to OPG in favour of RANKL, which may lead to enhance osteoclastogenesis resulting in bone resorption [33].

We next wished to investigate the effects of molecules released by OSCC cells on osteoclast behaviour (Pathway C, Fig. 8). Unexpectedly, when CM of OSCC cells was added into cultures of Raw264.7 cells, we could not see osteoclast formation (data not shown). Thereafter, we firstly obtained mature osteoclasts from Raw 264.7 cells, and treated them with CM of OSCC cells grown with or without TGF- $\beta 1$. Our results showed that CM from cells pre-treated with TGF- $\beta 1$ prolonged osteoclast survival up to 4 days compared with CM without TGF- $\beta 1$. With continued RANKL treatment, mature osteoclasts became apoptotic on day 4 . TGF- $\beta 1(5 \mathrm{ng} / \mathrm{mL})$ also induced apoptosis of these osteoclasts. Thus, our results indicated that factors in OSCC cells treated by TGF- $\beta 1$ might block its apoptotic effects, and promote survival of osteoclasts.
Cytokines induced by TGF- $\beta 1$ may include pathways of apoptosis, such as caspase or BCL family members, which needs to be further investigated.

The question of whether changes in the fibroblastshaped neoplastic cells are necessary for these to acquire osteomimetic characteristics remains $[34,35]$. Davies et al. [36] found that transfection of TGF- $\beta 1$ into a rat keratinocyte cell line caused changes in cell morphology from polygonal to spindle: these cells subsequently formed tumours in nude mice, and increased local bone resorption. Takayama et al. [37] reported that TGF- $\beta 1$ caused EMT of SCCVII cells, and they found EMT-like changes through resected human mandibles with gingival SCC, in which immunohistochemical staining of E-cad was weak in tumour mass-margin comparing with the tumour masscentre. Although changes of cell morphology (indicative of EMT) was not observed during the 3 day treatments with TGF- $\beta 1$, OSCC cells coordinated the survival of osteoclasts. Further validation of molecules in OSCC tissue samples found stronger staining of CK and Snail1, while weaker staining of VIM and E-cad, which are consistent with Takayama's results. Although these findings are indirect observation, which are not substantial, they suggest that partial EMT may exist in the bone invasive progression of OSCC. Whether morphologic and phenotypic changes of malignant keratinocytes are necessary for bone invasion is the focus of future work [38].

Acknowledgments This study was supported by funds from China Scholarship Council (2008638008), Griffith University Postgraduate Research Scholarship (GUPRS), National Health and Medical Research Council (NHMRC) Australia-China Exchange Fellowship, and Australian Dental Research Foundation (ADRF). We would like to thank Dr. Saeed M Hashimi (Griffith University, Australia) for the proof-reading of the manuscript.

Conflict of interest We declare to have none conflict of interest.

Open Access This article is distributed under the terms of the Creative Commons Attribution License which permits any use, distribution, and reproduction in any medium, provided the original author(s) and the source are credited.

\section{References}

1. Chen YL, Kuo SW, Fang KH, Hao SP (2011) Prognostic impact of marginal mandibulectomy in the presence of superficial bone invasion and the nononcologic outcome. Head Neck 33:708-713

2. Lubek J, El-Hakim M, Salama AR, Liu X, Ord RA (2011) Gingival carcinoma: retrospective analysis of 72 patients and indications for elective neck dissection. Br J Oral Maxillofac Surg 49:182-185

3. Shaw RJ, Brown JS, Woolgar JA, Lowe D, Rogers SN, Vaughan ED (2004) The influence of the pattern of mandibular invasion on recurrence and survival in oral squamous cell carcinoma. Head Neck 26:861-869

4. Ebrahimi A, Murali R, Gao K, Elliott MS, Clark JR (2011) The prognostic and staging implications of bone invasion in oral squamous cell carcinoma. Cancer 117:4460-4467 
5. Quan J, Johnson NW, Zhou G, Parsons PG, Boyle GM, Gao J (2012) Potential molecular targets for inhibiting bone invasion by oral squamous cell carcinoma: a review of mechanisms. Cancer Metastasis Rev 31:209-219

6. Martin CK, Werbeck JL, Thudi NK et al (2010) Zoledronic acid reduces bone loss and tumor growth in an orthotopic xenograft model of osteolytic oral squamous cell carcinoma. Cancer Res 70:8607-8616

7. Santini D, Galluzzo S, Zoccoli A et al (2010) New molecular targets in bone metastases. Cancer Treat Rev 36:S6-S10

8. Sterling JA, Edwards JR, Martin TJ, Mundy GR (2011) Advances in the biology of bone metastasis: how the skeleton affects tumor behavior. Bone 48:6-15

9. Taylor MA, Parvani JG, Schiemann WP (2010) The pathophysiology of epithelial-mesenchymal transition induced by transforming growth factor-beta in normal and malignant mammary epithelial cells. J Mammary Gland Biol Neoplasia 15:169-190

10. Juárez P, Guise TA (2011) TGF- $\beta$ in cancer and bone: implications for treatment of bone metastases. Bone 48:23-29

11. Padua D, Massagué J (2009) Roles of TGF-beta in metastasis. Cell Res 19:89-102

12. Zavadil J, Böttinger EP (2005) TGF-beta and epithelial-tomesenchymal transitions. Oncogene 24:5764-5774

13. Mohammad KS, Javelaud D, Fournier PG et al (2011) TGF-betaRI kinase inhibitor SD-208 reduces the development and progression of melanoma bone metastases. Cancer Res 71:175-184

14. Ganapathy V, Ge R, Grazioli A et al (2010) Targeting the Transforming Growth Factor-beta pathway inhibits human basallike breast cancer metastasis. Mol Cancer 9:122

15. Goda T, Shimo T, Yoshihama Y et al (2010) Bone destruction by invading oral squamous carcinoma cells mediated by the transforming growth factor-beta signalling pathway. Anticancer Res 30:2615-2623

16. Prime SS, Eveson JW, Stone AM et al (2004) Metastatic dissemination of human malignant oral keratinocyte cell lines following orthotopic transplantation reflects response to TGF-beta 1. J Pathol 203:927-932

17. Quan J, Zhou C, Johnson N, Francis G, Dahlstrom J, Gao J (2012) Molecular pathways involved in crosstalk between cancer cells, osteoblasts and osteoclasts in the invasion of bone by oral squamous cell carcinoma. Pathology 44:221-227

18. Micalizzi DS, Ford HL (2009) Epithelial-mesenchymal transition in development and cancer. Future Oncol 5:1129-1143

19. Qiao B, Johnson NW, Gao J (2010) Epithelial-mesenchymal transition in oral squamous cell carcinoma triggered by transforming growth factor-beta1 is Snail family-dependent and correlates with matrix metalloproteinase- 2 and -9 expressions. Int $\mathbf{J}$ Oncol 37:663-668

20. Christofori G (2003) Changing neighbours, changing behaviour: cell adhesion molecule-mediated signalling during tumour progression. EMBO J 22:2318-2323

21. Smit MA, Geiger TR, Song JY, Gitelman I, Peeper DS (2009) A Twist-Snail axis critical for TrkB-induced epithelial- mesenchymal transition-like transformation, anoikis resistance, and metastasis. Mol Cell Biol 29:3722-3737

22. Waldmann J, Slater EP, Langer P et al (2009) Expression of the transcription factor snail and its target gene twist are associated with malignancy in pheochromocytomas. Ann Surg Oncol 16: 1997-2005

23. Yang MH, Chen CL, Chau GY et al (2009) Comprehensive analysis of the independent effect of twist and snail in promoting metastasis of hepatocellular carcinoma. Hepatology 50:1464-1474

24. Kessenbrock K, Plaks V, Werb Z (2010) Matrix metalloproteinases: regulators of the tumor microenvironment. Cell 141:52-67

25. Brew K, Nagase H (2010) The tissue inhibitors of metalloproteinases (TIMPs): an ancient family with structural and functional diversity. Biochim Biophys Acta 1803:55-71

26. Derynck R, Akhurst RJ, Balmain A (2001) TGF-beta signaling in tumour suppression and cancer progression. Nat Genet 29:117-129

27. Hagedorn HG, Bachmeier BE, Nerlich AG (2001) Synthesis and degradation of basement membranes and extracellular matrix and their regulation by TGF-beta in invasive carcinomas. Int J Oncol 18:669-681

28. Lynch CC (2011) Matrix metalloproteinases as master regulators of the vicious cycle of bone metastasis. Bone 48:44-53

29. Woodward JK, Holen I, Coleman RE, Buttle DJ (2007) The roles of proteolytic enzymes in the development of tumour-induced bone disease in breast and prostate cancer. Bone 41:912-927

30. Krane SM, Inada M (2008) Matrix metalloproteinases and bone. Bone 43:7-18

31. Hikita A, Yana I, Wakeyama $\mathrm{H}$ et al (2006) Negative regulation of osteoclastogenesis by ectodomain shedding of receptor activator of NF-kappaB ligand. J Biol Chem 281:36846-36855

32. Sabbota AL, Kim HR, Zhe X, Fridman R, Bonfil RD, Cher ML (2010) Shedding of RANKL by tumour-associated MT1-MMP activates Src-dependent prostate cancer cell migration. Cancer Res 70:5558-5566

33. Dougall WC, Chaisson M (2006) The RANK/RANKL/OPG triad in cancer-induced bone diseases. Cancer Metastasis Rev 25:541-549

34. Zhau HE, Odero-Marah V, Lue HW et al (2008) Epithelial to mesenchymal transition (EMT) in human prostate cancer: lessons learned from ARCaP model. Clin Exp Metastasis 25:601-610

35. Odero-Marah VA, Wang R, Chu G et al (2008) Receptor activator of NF-kappaB Ligand (RANKL) expression is associated with epithelial to mesenchymal transition in human prostate cancer cells. Cell Res 18:858-870

36. Davies M, Prime SS, Stone AM, Huntley SP, Eveson JW, Paterson IC (2000) Endogenous TGF-betal inhibits the growth and metastatic dissemination of rat oral carcinoma cell lines but enhances local bone resorption. J Oral Pathol Med 29:232-240

37. Takayama Y, Mori T, Nomura T, Shibahara T, Sakamoto M (2010) Parathyroid-related protein plays a critical role in bone invasion by oral squamous cell carcinoma. Int $\mathrm{J}$ Oncol 36: 1387-1394

38. Van der Pluijm G (2011) Epithelial plasticity, cancer stem cells and bone metastasis formation. Bone 48:37-43 